\title{
Comparison of empirical use of low dose aspirin and enoxaprin in the treatment of unexplained recurrent pregnancy loss
}

\author{
Sunil Kumar Juneja, Pooja Tandon*, Gagandeep Kaur, Bakul Kapoor, Guneet Singh Sidhu
}

Department of Obstetrics and Gynecology, Dayanand Medical College and Hospital, Ludhiana, Punjab, India

Received: 24 December 2019

Revised: 24 January 2020

Accepted: 29 January 2020

\author{
*Correspondence: \\ Dr. Pooja Tandon, \\ E-mail: drpoojatandon77@gmail.com
}

Copyright: (C) the author(s), publisher and licensee Medip Academy. This is an open-access article distributed under the terms of the Creative Commons Attribution Non-Commercial License, which permits unrestricted non-commercial use, distribution, and reproduction in any medium, provided the original work is properly cited.

\begin{abstract}
Background: Recurrent pregnancy losses have commonly been defined as three or more consecutive spontaneous pregnancy losses. About 1-2\% of women suffer from recurrent miscarriages. The cause is multifactorial such as uterine anomalies, endocrine disorders, immunological causes, infections, chromosomal anomalies and maternal autoimmune diseases. In 50-60\% of cases recurrent pregnancy losses, the cause remains unclear. Objective of this study was to compare the maternal and fetal outcome in patients with unexplained recurrent pregnancy loss treated with LMWH (Enoxaparin) vs Aspirin during pregnancy.

Methods: Women with 3 or more pregnancy losses, aged between 18-40 years, booked for antenatal care and delivery in our hospital between January 2012 and December 2016 were followed till 6 months after delivery.

Results: A total number of 146 women were assessed for eligibility. We had 62 women in Group A (aspirin group) and 84 women in Group E (enoxaparin group). Enoxaparin was given to all those ladies who had taken aspirin in previous pregnancies with no live outcome. Good neonatal outcome was observed with Enoxaparin.

Conclusions: Live birth rates did not show significant difference between the two study groups. But empirical use of enoxaparin in patients with no live birth who have taken low dose aspirin in previous pregnancy had shown improved results, so enoxaparin should be used empirically as a first line agent in such cases.
\end{abstract}

Keywords: Aspirin, Enoxaparin, Low molecular weight heparin, Pregnancy, Recurrent, Unexplained

\section{INTRODUCTION}

Recurrent pregnancy losses have commonly been defined as three or more consecutive spontaneous pregnancy losses. ${ }^{1}$ Chromosomal abnormalities have been seen in $10-15 \%$ of miscarriages. About $1-2 \%$ of women suffer from recurrent miscarriages. ${ }^{2,3}$ The cause is multifactorial such as uterine anomalies, endocrine disorders, immunological causes, infections, chromosomal anomalies and maternal autoimmune diseases. In 50-60\% of cases recurrent pregnancy losses, the cause remains unclear. ${ }^{4,5}$ In large meta-analysis different thrombophilia polymorphism has been identified to be associated with recurrent fetal loss. Therefore, interventions with thromboprophylaxis for the prevention of recurrent miscarriages have been proposed. ${ }^{6}$ According to some authors thrombophilia markers are not the only criteria for the initiation of the treatment. ${ }^{7}$ Whereas other investigators suggest not to treat unexplained miscarriage without evidenced antiphospholipid syndrome or inherited thrombophilia. It is well known fact that thrombosis is common at placental level whether antiphospholipid antibodies are present or not, suggesting that other pathological mechanisms are involved leading to same outcome i.e. fetal loss. ${ }^{8}$ LMWH (low molecular weight heparin) and aspirin in low doses have been used empirically to prevent recurrent pregnancy losses. Though there is no consensus regarding the empirical use 
of antithrombotic therapy in unexplained pregnancy losses. ${ }^{9}$ LMHW is widely used as prophylaxis in recurrent miscarriages in general obstetric practice.

LMWH is most commonly used agent in the existing trials. In our trial, we aimed to investigate whether the use of LMWH improves live birth rate when compared to aspirin to know which thrombophylactic treatment is the best to prescribe to women with recurrent miscarriage without known cause of thrombophilia.

Objective of this study was to compare the maternal and fetal outcome in patients with unexplained recurrent pregnancy loss treated with LMWH (Enoxaparin) versus Aspirin.

\section{METHODS}

Women with 3 or more pregnancy losses, aged between 18-40 years, booked for antenatal care and delivery in our hospital between January 2012 and December 2016 were followed till 6 months after delivery.

\section{Inclusion criteria}

- All women had normal results for parental karyotyping, FBS, RFT, serum TSH, serum prolactin and homocysteine levels and all included patients had been screened negative for thrombophilia.

\section{Exclusion criteria}

- Women with cardiovascular disease, bleeding diathesis, previous thromboembolic phenomena, DM, vaginal bleeding, multiple pregnancies, smoking, morbid obesity, presence of contraindication for anticoagulants were also excluded.

Patients were divided into two groups, Group A received aspirin and Group $\mathrm{E}$ patients received LMWH (Enoxaparin). Group A (62 patients) and Group E with (84 patients), who had unexplained RPL were included in the study. Total 146 patients were followed throughout their pregnancy and delivered in our hospital. As soon as pregnancy was confirmed, Enoxaparin was given as $1 \mathrm{mg} / \mathrm{kg} /$ day as subcutaneous injection in all those patients who had taken aspirin in previous pregnancy and outcome was not good and aspirin as $75 \mathrm{mg}$ once a day orally in those patients who had not taken aspirin in previous pregnancy. All pregnant women underwent prenatal screening. Adherence of treatment was confirmed during follow up of patients. Patients were called every 2-3 weeks till 28 weeks, then every 2 weekly between 28-34 weeks, then weekly until delivery to assess fetal growth, fetal well-being and drug side effects. LMWH (enoxaparin) was stopped 12 hours before delivery. In preterm patients, aspirin was stopped with the onset of labour and was continued in patients who reached 36 weeks. Outcomes were listed as live birth rate, abortion rate, number of women with pre-eclampsia, IUGR, placental abruptions and drug side effects as thrombocytopenia thrombolic episodes, injection sites hematoma, subcutaneous bruises and allergic skin reaction.

All infants were examined by a paediatrician after delivery. Perinatal outcome in terms of birth weight, gestational week, number mortality, congenital anomalies were evaluated.

Data were described in terms of range; frequencies (number of cases) and relative frequencies (percentages) as appropriate. For comparing categorical data, Chi square $\left(\chi^{2}\right)$ test was performed and exact test was used when the expected frequency is less than 5. A probability value ( $p$ value) less than 0.05 was considered statistically significant. All statistical calculations were done using SPSS (Statistical Package for the Social Science) SPSS 17 version statistical program for Microsoft Windows.

\section{RESULTS}

A total number of 146 women were assessed for eligibility. We had 62 women in Group A (aspirin group) and 84 women in Group E (enoxaparin group).

Table 1: distribution of patients according to age of pregnant women.

\begin{tabular}{|lll|}
\hline Age & $\begin{array}{l}\text { Group A } \\
\text { (Aspirin) }\end{array}$ & $\begin{array}{l}\text { Group E } \\
\text { (Enoxaparin) }\end{array}$ \\
\hline$=25$ & 03 & \\
\hline$>25-30$ & 32 & 04 \\
\hline$>30-35$ & 21 & 45 \\
\hline$>35$ & 06 & 20 \\
\hline Total & $\mathbf{6 2}$ & 15 \\
\hline
\end{tabular}

Chi-square value $=2.972, \mathrm{p}$ value $=0.396$.

During this five-year period (January 2012 to December 2016), total number of deliveries were 5853 out of which 3626 were caesarean sections and 2227 were vaginal deliveries. In both our study groups, majority of the patients were between 25-30 years followed by $30-35$ years (Table 1).

Table 2: Distribution of patients according to number of abortions.

\begin{tabular}{|lll|}
\hline & Group A & Group E \\
\hline A3 & 43 & 53 \\
\hline A4-A6 & 15 & 24 \\
\hline$>$ A7 & 04 & 07 \\
\hline
\end{tabular}

Chi-square value $=0.636, \mathrm{p}$ value $=0.727$.

All the patients enrolled in the study had more than three consecutive abortions. Fifteen patients in Group A and 24 patients in Group E had 4-6 abortions. Four patients in 
Group A and seven patients in Group E had seven or more than seven abortions (Table 2).

Table 3: Distribution of patients according to gestational age.

\begin{tabular}{|lll|}
\hline Gestation (in weeks) & Group A & Group E \\
\hline$=28$ & 03 & 04 \\
\hline$>28-32$ & 18 & 26 \\
\hline$>32-36$ & 28 & 36 \\
\hline$>36-40$ & 13 & 18 \\
\hline Total & $\mathbf{6 2}$ & $\mathbf{8 4}$ \\
\hline
\end{tabular}

Chi-square value $=0.0908$, p-value $=0.993$.
Majority of the patients in both the groups delivered between 32-36 weeks gestation (Table 3) with maximum number of live births (Table 4).

Maximum number of IUGR babies were born between 32-36 weeks gestation in both the groups. There were four neonatal deaths, three in Group A and one in Group E (Table 5). More number of patients delivered vaginally in Group A as compared to Group E though the difference was not statistically significant (Table 6). Placenta previa, placental abruption, PIH (pregnancy induced hypertension), and PPH (postpartum hemorrhage) incidence was comparable in both the groups (Table 7).

Table 4: Distribution of patients according to fetal outcome.

\begin{tabular}{|c|c|c|c|c|}
\hline & Liveborn & Liveborn & Abortion/stillborn & Abortion/stillborn \\
\hline POG (weeks) & Group A & Group E & Group A & Group E \\
\hline$<28$ & 0 & 03 & 3 & 1 \\
\hline $28-32$ & 15 & 24 & 3 & 2 \\
\hline $32-36$ & 24 & 35 & 4 & 1 \\
\hline $36-40$ & 12 & 18 & 1 & 0 \\
\hline Total & 51 & 80 & 11 & 4 \\
\hline
\end{tabular}

Liveborn chi-square value $=0.0407, \mathrm{p}$ value $=0.938$, stillborn chi-square value $=0.938, \mathrm{p}$ value $=0.816$

Table 5: Distribution of patients according to IUGR and NND.

\begin{tabular}{|lllll|}
\hline & IUGR & IUGR & NND & NND \\
\hline 28 weeks & Group A & Group E & Group A & Group E \\
\hline$>28-32$ & 0 & 0 & 0 & 0 \\
\hline$>32-36$ & 3 & 4 & 2 & 1 \\
\hline$>36-40$ & 8 & 6 & 1 & 0 \\
\hline Total & 4 & 4 & 0 & 0 \\
\hline
\end{tabular}

IUGR chi-square value $=0.395, \mathrm{p}$ value $=0.821, \mathrm{NND}$ chi-square value $=0.444, \mathrm{p}$ value $=0.505$.

Table 6: Distribution of patients according to mode of delivery.

\begin{tabular}{|lllll|} 
& LSCS & LSCS & Vaginal delivery & Vaginal delivery \\
\hline 28 weeks & Group A & Group E & Group A & Group E \\
\hline$>28-32$ & $\mathbf{0}$ & $\mathbf{0 2}$ & $\mathbf{0 3}$ & $\mathbf{0 2}$ \\
\hline$>32-36$ & 9 & 20 & 8 & 6 \\
\hline$>36-40$ & 14 & 24 & 12 & 12 \\
\hline Total & 2 & 10 & 11 & 7 \\
\hline
\end{tabular}

LSCS chi-square value $=1.726, \mathrm{p}$ value $=0.631$, vaginal chi-square value $=0.579, \mathrm{p}$ value $=0.901$.

Table 7: Distribution of patients according to APH, PPH and PIH.

\begin{tabular}{|lll|} 
& Group A & Group E \\
\hline Placental previa & 13 & 12 \\
\hline Placental abruption & 03 & 01 \\
\hline PPH & 04 & 02 \\
\hline PIH & 09 & 11 \\
\hline
\end{tabular}

Placenta previa chi-square value $=1.122, \mathrm{p}$ value $=0.284$, placental abruption chi-square value $=1.437, \mathrm{p}$ value $=0.231, \mathrm{PPH}$ chisquare value $=1.124, \mathrm{p}$ value $=0.288$, PIH chi-square value $=0.061$, $\mathrm{p}$ value $=0.085$. 


\section{DISCUSSION}

Recurrent miscarriage (RM) is defined as three or more consecutive miscarriages occurring before 20 weeks postmenstruation. ${ }^{10}$ Around $1 \%$ of fertile couples will experience recurrent early pregnancy losses. ${ }^{11}$ The risk of recurrence increases with the maternal age and number of successive losses. ${ }^{12}$ Recurrent miscarriage has been directly associated with parental chromosomal abnormalities, maternal thrombophilic disorders and structural uterine anomalies. ${ }^{13,14}$ Maternal immune dysfunction and endocrine abnormalities have also been postulated in recurrent pregnancy losses. ${ }^{14}$

The majority of cases of recurrent pregnancy losses following investigation are classified as idiopathic, that is, no identifiable cause is identified in either partner. It is generally accepted that within the idiopathic group there is considerable heterogeneity and it is unlikely that one single pathological mechanism can be attributed to their recurrent miscarriage history. ${ }^{10}$ Current research is directed at theories on defects in nature's quality control related to implantation, trophoblast invasion and placentation, as well as factors, which may be embryopathic. ${ }^{15}$

High-quality data on the management of RPL (recurrent pregnancy loss) are limited and reported studies on the aetiology, evaluation and management of RPL are mostly observational. For these reasons, therapeutic recommendations are largely based on clinical experience and data from these observational studies. ${ }^{16}$

\section{Acetylsalicylic acid}

Low-dose aspirin is an antiplatelet agent which irreversibly inhibits platelet cyclo-oxygenase and thereby decreases the production of thromboxane A2 (TXA2), a potent vasoconstrictor and platelet activator. The hypothesis of an impaired placental circulation due to microthrombosis as a cause of RPL is the background for treatment with ASA. ${ }^{17}$

LMWHs have been found to be effective in improving live birth rate even in the absence of demonstrated etiologic factors. Many properties of heparin have been used for this purpose. Besides anticoagulant activity, heparin has an anti-inflammatory effect that decidua's from women with recurrent miscarriages show common pathology that necrosis, acute and chronic inflammation and vascular thrombosis compared with those of women with normal pregnancies. ${ }^{18}$ Also heparin has an anticomplement effect which is absolutely required to prevent pregnancy loss and thrombosis. ${ }^{19,20}$

\section{CONCLUSION}

Live birth rates did not show significant difference between the two study groups. but empirical use of enoxaparin in patients with no live birth who had taken ecosprin in previous pregnancy showed improved results, so Enoxaparin should be used empirically as a first line agent in patients with recurrent pregnancy loss.

Funding: No funding sources

Conflict of interest: None declared

Ethical approval: The study was approved by the Institutional Ethics Committee

\section{REFERENCES}

1. Jauniaux E, Farquharson RG, Christiansen OB, Exalto N. Evidence-based guidelines for the investigation and medical treatment of recurrent miscarriage. Hum Reprod. 2006;21:2216-22.

2. Salat-Baroux J. Recurrent spontaneous abortions. Reprod Nutr Dev. 1988;28:1555-68.

3. Tulppala M, Palosuo T, Ramsay T, Miettinen A, Salonen R, Ylikorkala O. A prospective study of 63 couples with a history of recurrent spontaneous abortion: contributing factors and outcome of subsequent pregnancies. Hum Reprod. 1993;8(5):764-770.

4. Christiansen OB, Andersen AM, Bosch E, Daya S, Delves PJ, Hviid TV, et al. Evidence-based investigations and treatments of recurrent pregnancy loss. Fertil Steril. 2005;83:821-39.

5. Regan 1, Rai R. Epidemiology and the medical causes of miscarriage. Baillieres Best Pract Res Clin Obstet Gynaecol. 2000;14:839-54.

6. Rey E, Kahn SR, David M, Shrier I. Thrombophilic disorders and fetal loss: a meta-analysis. Lancet. 2003;361:901-8.

7. Dolitzky M, Inbal A, Segal Y, Weiss A, Brenner B, Carp H. A randomized study of thromboprophylaxis in women with unexplained consecutive recurrent miscarriages. Fertil Steril. 2006;86:362-26.

8. Duhl AJ, Paidas MJ, Ural SH. Antithrombotic therapy and pregnancy: consensus report and recommendations for prevention and treatment of venous thromboembolism and adverse pregnancy outcomes. Am J Obstet Gynecol. 2007;197:457.

9. Omri A, Delaloye JF, Anderson H, Bachman F. Low molecular weight heparin Novo (LHN-1) does not cross the placenta during the second trimester of pregnancy. Thromb Haemost. 1989;61:55-6.

10. Stirrat GM. Recurrent miscarriage: definition and epidemiology. Lancet. 1990;336:673-5.

11. Berry CW, Bramabati B, Eskes TKAB, Exalto N, Fox H, Geraedts JPM, et al. The euro team early pregnancy (ETEP) protocol for recurrent miscarriage. Hum Reprod. 1995;10:1516-20.

12. Brigham SA, Conlon $\mathrm{C}$, Farquharson RG. A longitudinal study of pregnancy outcome following idiopathic recurrent miscarriage. Hum Reprod. 1999;14:2868-71.

13. Franssen MT, Korevaar JC, Leschot NJ, Bossuyt PM, Knegt AC, Gerssen-Schoorl KB, et al. Selective chromosome analysis in couples with two or more 
miscarriages: case-control study. BMJ. 2005;331:137-9.

14. Rey E, Kahn SR, David M, Shrier I. Thrombophilic disorders and fetal loss: a meta-analysis. Lancet. 2003;361:901-8.

15. Quenby S, Kalumbi C, Bates M, Farquharson R, Vince G. Prednisolone reduces preconceptual natural killer cells in women with recurrent miscarriage. Fertil Steril. 2005;84:980-4.

16. Christiansen OB, Nybo Andersen AM, Bosch E. Evidence-based investigations and treatments of recurrent pregnancy loss. Fertil Steril. 2005;83(4):821-39.

17. Flood K, Peace A, Kent E, Tedesco T, Dicker P, Geary $\mathrm{M}$, et al. Platelet reactivity and pregnancy loss. Am J Obstet Gynecol. 2010;203:281.

18. Van Horn, JT, Craven C, Ward K, Branch DW, Silver RM. Histologic features of placentas and abortion specimens from women with antiphospholipid and antiphospholipid like syndromes. Placenta. 2004;25:642-8.

19. Di Simone N, Ferrazzani S, Castellani R, De Carolis S, Mancuso S, Caruso A. Heparin and low-dose aspirin restore placental human chorionic gonadotrophin secretion abolished by antiphospholipid antibody-containing sera. Human Reprod. 1997;12:2061-5.

20. Walport MJ. Complement. N Engl J Med. 2001;344:1058-66.

Cite this article as: Juneja SK, Tandon P, Kaur G, Kapoor B, Sidhu GS. Comparison of empirical use of low dose aspirin and enoxaprin in the treatment of unexplained recurrent pregnancy loss. Int J Reprod Contracept Obstet Gynecol 2020;9:1138-42. 